\title{
Features of Research on Gender Aspects of Management Activity in Entrepreneurial Structures
}

\author{
Elena S. Afanaseva 1*[ORCID 0000-0001-9667-7347], \\ Magomed M. Omarov 1[ORCID 0000-0001-9853-4163], \\ Ivan L. Minin 1 [ORCID 0000-0003-3302-1767]
}

\author{
${ }^{1}$ Yaroslav-the-Wise Novgorod State University, Veliky Novgorod, Russia \\ Elena.Afanaseva@novsu.ru
}

\begin{abstract}
Currently, despite the development of management theory, many business leaders continue to ignore the specifics of gender relations in the management system. At the same time, in practice, it becomes necessary to take into account gender characteristics and make extraordinary management decisions for effective leadership both at the highest positions and at the lower level of the organizational and management structure of enterprises. The formed management theory needs to rethink the quality and improve the offered intra-corporate services; the relevance of assessing and taking into account the characteristics of gender aspects among other factors comes to the fore and requires a new approach. Gender characteristic is a concept that includes the behavioral characteristics of the male and female sexes, which are formed due to the cultural traditions of a society. The sign "gender" shows certain roles that are distributed in society, as well as social groups characterized by certain norms of ethics and rules of behavior. In practice, biological sex has three categories: socio-cultural, interactive and individual. The article reveals the relationship between gender and the style of management of the organization, and also defines the features of management, independent of the manager's gender. It has been proven that females are more sensitive to non-verbal expressions, and males are more prone to aggression, but they are better than females at adapting in mathematics. There are gender differences in governance, which are based not only on biological differences between the sexes, but also on social characteristics. In this regard, the theory and practice of management needs to rethink the gender aspect of management activities within corporations, which is associated with the activation of the position of women and their participation in the formation of certain social groups in the strategic period.
\end{abstract}

Keywords: gender characteristics, corporate policy, social groups, management, entrepreneurial structures

\section{INTRODUCTION}

In connection with the changes taking place in the global economy, modern management is becoming the sphere of influence of various aspects of the management structure. In the process of production in crisis conditions, it becomes necessary to make extraordinary management decisions for effective leadership both at the highest positions and at the lowest chain of the entrepreneurship hierarchy.

The continuing development of management theory proves the need to rethink the quality of services offered in the management system and assess the real situation and effective use of corporate personnel. This is largely due to the active position of women in the management system and their participation in the formation of certain social groups, especially in the developed countries of the world [1].

Recently, international studies of gender relations in the management system have expanded significantly, although, as a rule, they continue to be ignored in practice. In management theory since the 1960s studies of gender characteristics have been extensively conducted, mainly by psychiatrists from the UK and the USA. Since then, the concept of "gender" has been widely used not only to 
distinguish between male and female ego, but also to a large extent has come to mean a social and cultural construct [2].

With the help of various analytical technologies, managers of large corporations view the management system as a multipurpose body that governs the business, managers, employees and workflow. In practice, there are many management leadership perspectives, but gender diversity has not been recognized by any of them. Over the past decades, the presence of women managers in the management system has increased exponentially, with some of them being appointed to senior positions. In the scientific literature, there are also studies that refute the fact that men and women in the process of management act or behave differently [3].

\section{MATERIALS AND METHODS}

The purpose of the article is to identify the features of research on gender aspects of the management activities in entrepreneurial structures to determine the position of women in the modern structure of the organization and to identify the managerial role of gender in the national economy as a whole.

To achieve the goal, it is necessary to solve the following tasks:

- to define the essence of the concept of "social gender" and the features of its development in the capitalist formation;

- to identify the relationship between gender and the style of management of the organization, as well as to determine the characteristics of management, regardless of the gender of the manager;

- to consider the peculiarities of the gender factor in management activities using the example of Nefteprodukt, LLC (Russia).

The study used abstraction and modeling methods to create a conditional image of a female gender role, which is necessary to prevent mixing of gender social personality characteristics and create an ideal gender image without admixing the characteristics of upbringing and development inherent in the opposite sex.

To collect the data, we used the method of polling respondents in order to form an opinion of reflection and a subjective attitude towards the characteristics of a woman manager. The limitations of the method are based on a change in priorities from biological to social aspects of sex and the effect of gender splitting up to 16 categories, which may lead to insufficient research.

\section{RESULTS}

Studies have shown that in the system of entrepreneurship, gender differences are justified not only by biological differences between the sexes, but also by their social characteristics. The stereotypes that appeared in the 20th century have spread to all representatives of both male and female sex, regardless of individual characteristics, age, and social origin. These characteristics affect not only the behavioral qualities of a person (including those characteristics that are relevant to the study), but also the very process of making managerial decisions. In practice, gender characterization is the concept that the characteristics and behavior of the male and female sexes are shaped by the cultural traditions of a society. The sign "gender" shows certain roles that are distributed in society, as well as social groups, including the norms of ethics and law [4]

Gender characteristics are determined not only by target categories, but also by the nature of social relations between women and men. In the course of research, it has been proven that gender provides for a structure of relationships that can focus both on reproduction and on a set of procedures that will be further controlled by this structure. Such characteristics make it possible to distinguish between reproduction at the physical level, as well as in social management processes [5].

Observation of managers at Nefteprodukt, LLC (Russia) showed that the meaning of gender in practice varies greatly according to different parameters. Thus, gender is of great importance for human resource management, team building and leadership. Likewise, in marketing, sales and advertising, gender relevance is significant.

In the course of the research, we prepared a questionnaire for management specialists with "Yes / No" options. The questions covered the assessment of the importance of gender as a part of management education, as well as the influence of gender factors on career growth, wages, responsibility and teamwork. Of the 30 managers and 120 employees of Nefteprodukt, LLC, all of them gave a complete answer to the surveyed questions of the questionnaire.

The respondents were asked to express their opinion on whether gender matters in management 
education and management practice $(90 \%$ gave a positive answer). The first stage of the study showed that respondents understand gender mainly as a biological sex. The quantitative study revealed a number of different perceptions among gender workers in relation to management functions; some cases are controversial. Despite the best education of women, there is a perception that a male manager must succeed in a corporate career or rise higher in the management hierarchy. The majority of respondents $(60 \%)$ stated that gender plays an important role in career advancement. However, $40 \%$ believe that gender is not the determining factor. The respondents were asked how they assess the influence of the gender factor on the size of wages. $30 \%$ of respondents do not believe that wages and pay structure have anything to do with the gender of the employee. At the same time, male managers receive higher wages, have better job security, occupy higher positions in order to be less stressed, able to spend more time on each level of responsibility and not experience any prejudice and discrimination. A majority $(75 \%)$ of respondents believe that gender plays a role in recruiting staff for jobs, roles and responsibilities assigned in organizations. The results of the second phase of the study showed that respondents place greater emphasis on gender in relation to some aspects of managerial and organizational dynamics.

The obtained results of the study of gender relations showed that the biological sex in practice has three categories of analysis: socio-cultural, interactive, individual.

1) Socio-cultural category. At this level, biological sex factors affect access to resources (for example, professions that are divided into female and male); female occupations and employment categories are often viewed as less important in the modern world.

2) Interactive category. This concept assumes a situation in which males and females relate completely differently to everyday processes and interactions, and due to this they behave within the framework of the deduction of their gender. It happens that a man and a woman behave in the same way, but all the same, their manifestation is interpreted by society in completely different ways. Then gender characteristics can exist independently of each other.

3) Individual category. At this level of the category, gender is considered dichotomous and shows that a person can be male or female, while gender differences are accepted as part of self-esteem in society.

There are significant differences in the relationship between the anatomical and functional specifics of the brain structure in men and women. Many scientists believe that the female sex activates more of the brain than the male. Women have connected hemispheres, so they use emotions in a pronounced form, unlike men. The female gender can normalize imbalances when emotions and analytical thinking are fine lines and don't mix. In the entrepreneurship system, the female sex is more sensitive to non-verbal expressions. The male sex is considered to be more prone to aggression, but they are better than women at adapting to mathematics. Many researchers argue that most personality dimensions involve greater differences between individuals than between gender itself. At the same time, the male and female sex are becoming more and more similar to each other. Research in the intercultural sphere reflects differences not only in the concept of gender characteristics and roles, but also differences in cultures themselves, because this is determined by the specifics of the biological sex.

The widely accepted theory of the "glass ceiling" is a metaphor for a "ceiling" in a career - the existence of prejudice and gender discrimination, attitudes towards women leaders and potential women leaders with prejudices unrelated to their professional qualities, which manifests itself in multiple consequences. Prejudice can take subtle or overt forms and can be promoted by employers, clients, voters, and even the subjects of prejudice themselves. Bias against women as leaders hinders the development of women's ability to gain authority and influence, leading to discrimination in personnel decisions within organizations and political structures. In practice, sociologists and psychologists study prejudice, while industrial and organizational research studies managerial roles and organizational processes. Analyzing the situation of women leaders often biases their leadership competencies and capacities, indicating that, in a wide variety of settings and contexts, women are perceived to be less competent and therefore less worthy of leadership positions.

Research from the United States, Germany, the United Kingdom, China and Japan shows that men consider themselves to be more skilled managers than women. In addition, changing perceptions of governance over time have sparked a growing debate as to why men from different countries with 
different political, economic and social views and backgrounds continue to view women as less competent to lead. The male gender has more leadership abilities, while the female has more personality characteristics (eg., honesty, lack of selfishness), which is in line with traditional gender stereotypes. Citing additional evidence of bias against women, the research shows stricter standards for recruiting women, which make applicants less likely to hire women than men.

Empirical research examining the pressure on female job seekers has shown that male agents are considered to be more socially qualified than female agents. In addition, men are more suitable for recruitment than women applying for jobs requiring community skills. However, women with both agent and community qualities are considered to be as employable as their male counterparts, regardless of job requirements. Leadership has traditionally been viewed as a man's business with special challenges and pitfalls for women. This perception demonstrates the similarities and differences in how men and women perceive themselves as leaders and participate in leadership [6].

Theorists in their scholarly writings often examine the question "In practice, are there any gender differences in leadership style?" Recent research on transformational and transactional leadership concludes that male and female leaders are very similar in a number of ways, but generally behave differently. In practice, both men and women expect to take the lead in areas that are relatively traditional for their gender [7].

At the same time, men prefer to lead in business, and women - in the field of education. Women expect more difficulties in their personal relationships and other negative consequences as a result of their leadership. Foreign researchers in their works are trying to find out why women are underestimated in leadership positions and are prone to reductions based on gender [8].

In practice, many companies are working on a "gender equality" strategy. Of particular interest are HR managers who are focused on interviewing in the context of the various scales of the applicant company, ensuring gender equality [9].

Small companies can actually be only a fraction of large global corporations with several divisions. Being part of the top management of the former may mean being in the middle management of the latter, although at first glance it may seem that both companies are active in gender politics, and their classification into the "active group" is reasonable [10].

The relationship between the contexts of corporate policy and the individual positioning of chief HR managers is shown in Table 1.

Table 1. Relationship between corporate policy contexts and individual positions

\begin{tabular}{|c|c|c|c|c|}
\hline \multicolumn{5}{|c|}{ Individual Positioning } \\
\hline 을 & & Negative & Neutral & Positive \\
\hline 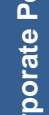 & $\begin{array}{c}\text { Negative } \\
\text { context of } \\
\text { gender equality }\end{array}$ & Stable & $\begin{array}{c}\text { In } \\
\text { suspense }\end{array}$ & $\begin{array}{l}\text { Comple- } \\
\text { mentary }\end{array}$ \\
\hline 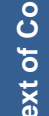 & $\begin{array}{l}\text { Neutral context } \\
\text { of gender } \\
\text { equality }\end{array}$ & $\stackrel{\text { In }}{\text { suspense }}$ & $\begin{array}{l}\text { Comple- } \\
\text { mentary }\end{array}$ & $\begin{array}{c}\text { In } \\
\text { suspense }\end{array}$ \\
\hline ¿े & $\begin{array}{l}\text { Positive context } \\
\text { of gender } \\
\text { equality }\end{array}$ & $\begin{array}{l}\text { Comple- } \\
\text { mentary }\end{array}$ & $\begin{array}{c}\text { In } \\
\text { suspense }\end{array}$ & Stable \\
\hline
\end{tabular}

Source: Compiled by the authors

In a corporate governance system that is more active in the area of gender equality, employees with different positions in relation to gender power and gender equality can be promoted. Individual positioning reinforces the dominant organizational context of candidates for leadership positions. As with resistance in general, it can be active or passive, more or less based on resistance through constancy or distance. A neutral recruiting manager in practice tends to provide more detailed information on gender issues than a negative recruiting manager. Having integrated gender and diversity issues to some extent, he is more open about gender issues. In contrast, elements of gender hierarchy, sexism and paternalism were present in interviews with a neutral company HR-manager. The HR-manager with positive attitudes was the opposite of the principles of the company with a neutral attitude, since he worked in a corporate environment that was not active in developing gender policy [11].

Thus, compatibility between agents and organizations, albeit in negative mode, is an acceptable situation. The staff tries to understand the gender situation and the controversies around it, referring to what can be called "outsiders" and their own "reasonable individual intentions" and "reasonable organizational policies" (corporate or singular), without trying to highlight the issue of discrimination. In this situation, the processes of structural reproduction of sex, gender differences and gender power, including gender relations between men and women, gender inequality 
between organizations, have not been identified [12].

In the management system, the principles of gender policy are developed and implemented for the entire organization, but they, often, cannot be reproduced in practical behavior (with a predominance of men) in a unit or an individual manager. In such practices, gender structures are reproduced [13].

Research shows that women often complain about inequalities in the opportunities for growth in responsibility associated with managerial roles and functions. Other studies justify the superiority of either sex for being effective and efficient in its own way. Further research is needed as to whether inequality in governance is more stereotypical in nature than in other areas of life, or whether it is etched into the minds of today's business managers as well as future leaders.

\section{DISCUSSION}

Foreign researchers believe that in male cultures, an individual should be assertive, decisive, tough and have a more stable financial position, and in female cultures - more focused on the quality of life. Until now, countries such as Korea, China, Spain, USA, Sweden, Argentina, etc. are considered as male cultures, while Denmark, Holland, Norway and Chile belong to female cultures. Countries have certain cultural traditions that have found their way into the management structure. While in countries with a male culture, women are forced to obey the patterns that were invented by the male gender, in female cultures this is not required [14-15]. Many advanced industrial societies are approaching gender equality. In modern Russia, women have entered the paid labor force in large numbers; in addition, if in 1988 women accounted for $21 \%$ of managers, then over time their share increased rapidly and in 2019 reached almost $49 \%$ of the total number of managers.

\section{CONCLUSION}

Based on the results of the study, the following conclusions can be drawn.

1) For most working managers, gender is synonymous with the biological aspect. The social and cultural roles played by genders are central to discussions about the separation of males and females, but gender dimensions are not defined in terms of responsibility for the work performed, but are linked to biological sex.

2) Most leaders agreed that gender plays an important role in defining roles and responsibilities throughout the hierarchy. While male workers prefer to work in sales and travel, women prefer to work in the office or in the back office. Many respondents felt that their organizations were gender neutral in the allocation of responsibilities.

3) Management professionals are hired for their analytical skills that are independent of gender identity. Nonetheless, all of the employed and aspiring managers surveyed stated that gender plays an important role in the hiring process. Some organizations choose not to hire young professionals because they do not want to deal with girls who leave work due to marriage or maternity leave.

4) The situation with the female boss seems critical. While no one argued that they would have problems communicating with a female leader, most felt that many in their organization would be uncomfortable with having a female leader. Male authority influence is much more recognized.

5) Working women are very ethical in their approach, however, concerns were raised that they find many excuses for various losses and lost profits. In many organizations, faced with a shortage of labor or over-demand from clients for a period of time, employees were forced to work long hours, some managers feel that their female colleagues justify themselves by not working overtime, very often leaving a male colleague burdened.

6) In the course of the research, the problems of gender relations at Nefteprodukt, LLC (Russia) were assessed and as a result of the survey it was revealed that managers attach great importance to gender in management. Almost $45 \%$ of the survey respondents are female managers, which allows the results to be viewed as impartial.

\section{AUTHORS' CONTRIBUTIONS}

The authors made an equal contribution to the study: collection and analysis of material; definition of goals and objectives, research methods; formulation and scientific substantiation of 
conclusions, registration of key research results in the form of an article.

\section{REFERENCES}

[1] T.V. Dolzhenko, "Gender Management" [Gendernyi menedzhment], Economy and Society [Ekonomika i Sotsium], 2016, vol. 1(20), pp. 327-329. (In Russ.).

[2] G.S. Gabdreeva, A.R. Khalfieva, "A structural analysis of the complex of professionally important qualities of male and female managers", International Journal of Environmental and Science Education, 2016, vol. 11(3), pp. 339-347. DOI: 10.12973/ijese.2016.320a

[3] G. Blanki, K. Olas, "A woman runs her business in the way she equips her house..." [Zhenshchina vedet svoy biznes tak, kak ona obustraivayet svoy dom...], Science and Life, [Nauka i Zhizn'], 2004, vol. 3, pp. 38-43. (In Russ.).

[4] I.A. Gvozdkova, "Gender aspects of the management activity organization”, Vestnik Universiteta, 2016, vol. 10, pp. 191-197. (In Russ.).

[5] A.V. Karpov, "Psychology of Management" [Psikhologiya upravleniya]: a tutorial, Moscow: Gardariki, 2005. (In Russ.).

[6] N.M. Kolosova, "Modern Model of Genomic and Other Research Regulations", Journal of Siberian Federal University. Humanities and Social Sciences, 2020, vol. 13(6), pp. 10201027. DOI: $10.17516 / 1997-1370-0611$

[7] M.Ia. Khrebtov, A.I. Fil'ko, "Historiographical Overview of the Research on the Transformation of the Russian People's Values", Journal of Siberian Federal University. Humanities and Social Sciences, 2020, vol. 13(5), pp. 738-751. DOI: 10.17516/19971370-0603

[8] E.O. Tarasova, V.N. Stegniy, L.N. Kurbatova, N.K. Okonskaya, M.A. Getashvili, "A study of the relation between work and family life of
Russian and American flight attendants", Astra salvensis, 2018, vol. 6(12), pp. 221-232.

[9] I.A. Belyaev, M.N. Lyashchenko, "SocioCultural Determinacy of Human Loneliness", Journal of Siberian Federal University. Humanities and Social Sciences, 2020, vol. 13(8), pp. 1264-1274. DOI: 10.17516/19971370-0640

[10]D. Popova, A. Pishniak, "Measuring individual material well-being using multimensional indises: an application using gender and generation survey for Russia”, Social Indicators Research, 2017, vol. 130(3), pp. 883-910. DOI: 10.1007/s11205-016-1231-7

[11] M.M. Omarov, N.Yu. Omarova, D.L. Minin, "Territory branding development as a regional economy activation factor", Lecture Notes in Networks and Systems, 2020, vol. 87, pp. 270277. DOI: 10.1007/978-3-030-29586-8_32

[12]E.E. Rogulina, "To the issue of national and cultural semantics of the Spanish colour idioms", Vestnik of Russian New University. Series: Man in the Modern World, 2018, vol. 3, pp. 75-82. (In Russ.). DOI: 10.25586/RNU.V925X.18.03.P.75

[13]S. Heldt, J.C. Rodriguez-de-Francisco, I. Dombrowsky, Ch. K. Feld, D. Karthe, "Is the EU WFD suitable to support IWRM planning in non-European countries? Lessons learnt from the introduction of IWRM and river basin management in Mongolia", Environmental Science and Policy, 2017, vol. 75, pp. 28-37.

[14] A.A. Shpak, D.S. Pchelkina, "Methodology for the Study of Complex Identity", Journal of Siberian Federal University. Humanities and Social Sciences, 2020, vol. 13(5), pp. 752-761. DOI: $10.17516 / 1997-1370-0604$

[15]M. Rodriguez, L. Miguel Sanchez, E. Cejudo, J. Antonio Camacho, "Variety in local development strategies and employment: LEADER programme in Andalusia", Agriculture Economy - Czech, 2019, vol. 65, pp. 43-50. DOI: 10.17221/106\%2F2018AGRICECON 